\title{
ARTIGO
}

CO https://doi.org/10.22481/praxisedu.v16i37.6024

\section{UMA ANÁLISE TRANSDISCIPLINAR SOBRE BRINQUEDOS E BRINCADEIRAS DE DIVERSAS REGIÕES DO BRASIL}

A TRANSDISCIPLINARY ANALYSIS ON TOYS AND TOYS OF VARIOUS REGIONS

OF BRAZIL

ANÁLISIS TRANSDISCIPLINARIO DE JUGUETES Y JUGUETES DE VARIAS

REGIONES DE BRASIL

Maria de Fátima Gomes da Silva

Universidade de Pernambuco-Brasil

Iolanda Mendonça de Santana

Universidade de Pernambuco-Brasil

Carla Fernanda Silva do Prado

Universidade de Pernambuco -Brasil

\begin{abstract}
Resumo: Este artigo apresenta resultados de uma pesquisa financiada pelo CNPq que teve por objetivo investigar vivências transdisciplinares, por meio de brinquedos e brincadeiras registrados em vídeos documentários do Programa Território do Brincar. Adotou-se para esta investigação a perspectiva de transdisciplinaridade defendida por Basarab Nicolescu (1999), sendo a análise dos dados orientada com base nos três pilares da metodologia transdisciplinar proposta por Nicolescu, a saber: os diferentes níveis de realidade, a lógica do terceiro termo incluído e a complexidade. Com relação aos procedimentos metodológicos, fez-se opção pela abordagem qualitativa. A coleta de dados foi realizada por meio da análise documental. Para a análise dos dados, fez-se uso da técnica de análise de conteúdo temáticocategorial. Os resultados permitiram concluir que os brinquedos e as brincadeiras analisadas proporcionaram às crianças vivências transdisciplinares na perspectiva da alteridade e do respeito ao pensamento do outro (lógica do terceiro termo incluído). Identificou-se, também, uma polissemia dos símbolos e diferentes vivências, convivências e aprendizagens (diferentes níveis de realidade) e uma conjugação de esforços no ato de brincar por meio do princípio dialógico (complexidade).
\end{abstract}

Palavras chave: Transdisciplinaridade; Brincadeiras; Território do Brincar.

\begin{abstract}
This article presents the results of a research financed by $\mathrm{CNPq}$, whose objective was to investigate transdisciplinary experiences through toys and games documented in videos of the Territory of Playing Program. For this research we adopted the perspective of transdisciplinarity defended by Basarab Nicolescu (1999). Data analysis was based on the three pillars of the transdisciplinary methodology proposed by Nicolescu, namely: different levels of reality, logic of the included middle, and complexity. Regarding the methodological procedures, the qualitative approach was chosen. Data collection was performed through documentary analysis. For data analysis, the technique of categorythematic content analysis was used. The results have allowed us to conclude that the toys and games analyzed provided children with transdisciplinary experiences within the perspective of otherness,
\end{abstract}


regarding the respect for the other's thinking (logic of the included middle). We have also identified a polysemy of symbols and different experiences, coexistence, and learning (different levels of reality) and a combination of efforts in the act of playing through the dialogical principle (complexity).

Keywords: Transdisciplinarity; Playing; Territory of Play.

Resumen: Este artículo presenta resultados de una investigación financiada por CNPqque tienen como objetivo investigar vivencias transdisciplinares, por medio de los juguetes y los juegos registrados en vídeos documentales del Programa Territorio del Juguetes. Adoptó para esta investigación al punto de vista de transdisciplinaridad defendida por Basarab Nicolescu (1999), haciendo el análisis de los datos orientada, basándose en los tres pilares de la metodología transdisciplinar propuesto por Nicolescu, a saber : los diferentes nivel de la realidad, la lógica del tercer término incluyendo la complexidad. En cuanto a los procedimientos metodológicos, se eligió el enfoque cualitativo. La recopilación de datos se realizó mediante análisis documental. Para el análisis de datos, se utilizó la técnica de análisis de contenido temático categórico. Los resultados permitieron concluir que los juguetes e los juegos examinados proporcionaron a los niños vivencias transdisciplinares en la perspectiva de la alteridad, en lo que se refieren al pensamiento del otro (lógica del tercer término incluso). Se identificó, también, una polisemia de los símbolos y diferentes vivencias, convivencias y aprendizajes (distintos niveles de la realidad) y una conjugación de esfuerzos en el ato de jugar por medio de los principios dialógicos (complexidad).

Palabras clave: Transdisciplinaridad; Juegos; Territorio de los Juegos.

\section{Introdução}

Este artigo reflete sobre vivências transdisciplinares do brincar no contexto de brinquedos e brincadeiras retratados em vídeos documentários do Programa Território do Brincar. Conforme foi anteriormente referido, adotou-se para este estudo a perspectiva de transdisciplinaridade proposta por Basarab Nicolescu (1999). Para o referido autor, a abordagem transdisciplinar propõe considerar uma realidade multidimensional, estruturada em múltiplos níveis, que substitua a realidade unidimensional do pensamento clássico.

Identificar vivências transdisciplinares no brincar das crianças aponta para a necessidade de ver a relação entre os sujeitos que brincam e o objeto do brincar, os brinquedos e as brincadeiras. É interessante pensar que os brinquedos e as brincadeiras carecem de sentidos, e isso vai acontecer pelas relações e conexões com os diferentes sujeitos em diferentes níveis de realidade no ato de brincar. O brincar tem, em si mesmo, uma complementaridade que transcende as dimensões explicativas e que necessita de outra lógica que é constitutiva de uma realidade de natureza complexa e transdisciplinar, a lógica do terceiro termo incluído. Nesse sentido, quando se realçam as interações entre sujeito e objeto no ato de brincar emergem novos 
sentidos, o que permite identificar diferentes níveis de realidade e diferentes níveis de percepção.

Sobre o Programa Território do Brincar, objeto empírico deste estudo, é de referir que se trata de um programa que é baseado na escuta e em intercâmbios de saberes sob a responsabilidade dos documentaristas Renata Meirelles e David Reeks, que percorreram o Brasil no período de abril de 2012 a dezembro de 2013, visitando comunidades rurais, indígenas, quilombolas, grandes metrópoles, sertão e litoral, o que permitiu revelar o país através dos olhos das crianças. Renata e David registraram as sutilezas da espontaneidade do brincar e nos apresentam a criança a partir dela mesma. Relatam os autores do referido Programa que em cada encontro surgiam intensas trocas e diálogos, por meio de gestos, expressões e saberes que foram cuidadosamente registrados em filmes, fotos, textos e áudios. O Território do Brincar se ampliou pela parceria firmada com o Instituto Alana, que é o correalizador do Programa, pelas escolas que acreditaram no valor dessa pesquisa e se tornaram parceiras, pelo apoio da aliança pela infância e de outras pessoas e organizações que muito enriquecem essa história. Ressalta-se a importância do Programa Território do Brincar no contexto educativo em espaços formais e não formais.

Assim sendo, no seguimento deste texto apresentam-se os procedimentos metodológicos adotados e, em seguida, reflete-se sobre as possíveis relações entre a transdisciplinaridade e o brincar. Na sequência, procede-se a uma análise transdisciplinar sobre brinquedos e brincadeiras do Programa Território do Brincar em diferentes regiões do Brasil. Nas considerações finais, faz-se uma síntese conclusiva das dimensões de análise que serviram de foco neste estudo, a lógica do terceiro termo incluído, os diferentes níveis de realidade e a complexidade, evidenciadas no processo dinâmico e na contínua interação entre as crianças por meio do brincar, pela integração, prazer, bem-estar, interatividade, imaginação, sensibilidade e criatividade presentes nas brincadeiras e ainda, pela unidade na diversidade ou a unidade múltipla materializada no ato de brincar.

\section{Os procedimentos metodológicos adotados}

Esta pesquisa foi orientada pelos princípios da abordagem qualitativa, uma vez que a referida abordagem permitiu uma melhor compreensão da problemática que foi objeto de estudo nesta investigação. De fato, a abordagem qualitativa coadunou-se com os objetivos da pesquisa que pretendeu identificar perspectivas transdisciplinares de brinquedos e brincadeiras de 
diversas regiões do Brasil retratadas em vídeos documentários do Programa Território do Brincar. Ressalta-se que os estudos centrados na abordagem qualitativa de pesquisa diferem entre si quanto ao método, à forma e aos objetivos. Godoy (1995, p. 62), ressalta a diversidade existente entre os trabalhos qualitativos e enumera um conjunto de características essenciais capazes de identificar uma pesquisa desse tipo, a saber: "o ambiente natural como fonte direta e o pesquisador como instrumento fundamental; o caráter descritivo; o significado que as pessoas dão às coisas e à sua vida como preocupação do investigador; enfoque indutivo".

Como recurso para a coleta de dados foi utilizada a análise documental. Sobre esse tipo de técnica refere Gil (2002, p. 62-63), que se trata de uma "fonte rica e estável de dados", isto porque não implica altos custos e possibilita uma leitura aprofundada das fontes. É semelhante à pesquisa bibliográfica, segundo o autor, o que as diferencia é a natureza das fontes, sendo material que ainda não recebeu tratamento analítico, ou que ainda pode ser reelaborado de acordo com os objetivos da pesquisa. Segundo Pádua (1997, p.62), a pesquisa documental "[...] tem sido largamente utilizada nas ciências sociais, na investigação histórica a fim de descrever/comparar fatos sociais, estabelecendo suas características ou tendências [...]”.

Para a realização da análise documental, foram construídos quadros com termos chave, nos quais foram registradas observações e/ou comentários sobre características transdisciplinares de brinquedos e brincadeiras retratados em vídeos do Programa Território do Brincar que estivessem circunscritas, de alguma forma, aos pilares da metodologia transdisciplinar proposta por Nicolescu (1999). Com essa pretensão, foram analisados gestos, expressões e saberes registrados em filmes, fotos, textos e áudios do Programa Território do Brincar que sinalizassem, de forma latente ou manifesta, para a vivência da transdisciplinaridade na perspectiva da lógica do terceiro termo incluído, dos diferentes níveis de realidade e da complexidade. Para este artigo, foram analisados vídeos documentários de seis brincadeiras, a saber: brincadeiras de palmas em diversas regiões do Brasil; brincadeira Pião de Biorra em Abadia, Minas Gerais; brincadeira pista com meninos, em Acupe, Bahia; brincadeira boi de pedra no Sertão do Ceará; brincadeira batizado de bonecas, em Abadia, Minas Gerais; brincadeira de casinhas no Vale do Jequitinhonha, Minas Gerais.

A análise dos resultados foi feita por meio da técnica de análise de conteúdo temáticocategorial, a qual foi orientada por dimensões de análise que foram construídas com base nos pilares que sustentam a metodologia transdisciplinar proposta por Nicolescu (1999), anteriormente referida. 


\section{Transdisciplinaridade no ato de brincar}

Neste ponto deste artigo, reflete-se sobre as possíveis relações entre a transdisciplinaridade e o brincar. Sobre a transdisciplinaridade, objeto teórico da pesquisa que deu origem a este artigo, afirma Follmann $(2005$, p. 56) que esta ajuda a “[...] recontextualizar os saberes, pois estes, sem contextualização, tornam-se vazios e emperrados [...]”. Com relação ao estudo aqui em foco, essa recontextualização de saberes foi perquirida no ato de brincar das crianças, uma vez que ao brincar, a criança interage e adquire novos conhecimentos. O brincar tem um papel fundamental na conquista da autonomia, da aprendizagem e da socialização da criança. Pena (2017, p. 81), afirma que “a brincadeira, para a criança, é um acontecimento; o lugar de encontro com a alteridade, no qual ela mergulha de corpo inteiro, cria e se compromete com o enredo inventado". Santos (2004, p.111), por outro lado, refere que a "[...] transdisciplinaridade diz respeito à dinâmica dos diferentes níveis de realidade [...]”. Foi possível, portanto, identificar nas brincadeiras que serviram de objeto de análise a este estudo diferentes níveis de realidade, uma vez que as crianças, durante as brincadeiras, estão inseridas num processo dinâmico e em contínua interação.

Para Silva (2009), a transdisciplinaridade consiste num nível superior da relação entre os saberes e que, por seu intermédio, os limites entre as diversas disciplinas tendem a desaparecer para dar lugar a um sistema total que ultrapassa o plano das relações e interações entre as disciplinas. Sobre o que refere Silva, nomeadamente sobre o fato de a transdisciplinaridade consistir "num nível superior da relação entre os saberes", pode-se dizer que os saberes presentes nas brincadeiras de vídeos documentários do Programa Território do Brincar aqui analisadas, de fato, permitiram às crianças ressignificar saberes transdisciplinarmente, uma vez que se identificou nas diversas brincadeiras analisadas a inclusão de um terceiro termo, o que possibilitou um movimento transdisciplinar que foi propiciado por relações entre diferentes saberes. Nessa perspectiva, convém referir Martins, Lechugo e Goergen (2013, p. 41, apud. PARENTE; NOVAES, 2017, p. 233), quando estes afirmam que "a educação transdisciplinar oferece ao indivíduo uma formação que ultrapassa as barreiras das disciplinas e proporciona um movimento para além do disciplinar”.

Rodrigues (2018, p. 2), entende a transdisciplinaridade como uma “[...] exigência de consagrar o diálogo entre diferentes campos do saber sem impor o domínio de uns sobre os outros [...]". E, nesse sentido, afirma que a transdisciplinaridade, 
Sugere muitos significados, desde aqueles capazes de incitar atraentes movimentos reflexivos, investigativos até reações de forte resistência e desconfiança, principalmente, se considerarmos a perspectiva polissêmica que a palavra é capaz de inspirar. (Ibid., p. 1).

No âmbito desta pesquisa, buscamos vivências transdisciplinares do brincar, no contexto de vídeos documentários sobre brinquedos e brincadeiras de diversas regiões do Brasil, registrados pelo Programa Território do Brincar. Assim sendo, o brincar foi aqui perquirido como uma expressão da transdisciplinaridade, o qual é motivado por uma dinâmica integradora em que estão entrelaçadas as várias dimensões humanas. Ressalta-se que este estudo evidenciou narrativas infantis sobre o brincar de diversas regiões brasileiras. Sobre as narrativas infantis, Canda, Soares e Zen (2018, p. 420) referem que estas “[...]revelam sentidos e significados impossíveis de serem conhecidos pelos adultos, senão pela própria interação com as crianças." Desse modo, as narrativas infantis sobre o brincar no âmbito desta pesquisa, surgem da interação entre as crianças no ato de brincar. Reitera-se que a transdisciplinaridade neste estudo foi tomada na acepção de Basarab Nicolescu (1999), que a conceitua como um movimento que se estabelece "entre", "através" e para "além" das disciplinas e que se consolida na "coerência", na "legitimidade" e na "articulação" de saberes. A finalidade da transdisciplinaridade "[...] é a compreensão do mundo atual, um dos imperativos é a unidade do conhecimento" (NICOLESCU, 1999, p. 22). Nicolescu (1999) sistematizou uma metodologia transdisciplinar que é sustentada por três pilares, ou seja, os diferentes níveis de realidade, a lógica do terceiro termo incluído e complexidade. Para Santos; Santos e Chiquieri (2009, p. 4), “[...] os três pilares da metodologia transdisciplinar estão mutuamente implicados [...]". Neste estudo, partiu-se do pressuposto de que o brincar é uma ação de natureza essencialmente transdisciplinar que está de certa forma, relacionada aos três pilares propostos por Nicolescu e, por isso, a análise de brinquedos e brincadeiras apresentadas nos vídeos documentários do Programa Território do Brincar no âmbito desta pesquisa foi feita com base nesses pilares.

Refere Nicolescu (1999, p. 46), que o objetivo da transdisciplinaridade é "[...] a compreensão do mundo presente, para o qual um dos imperativos é a unidade do conhecimento". Consideramos, pois, para esta investigação a necessidade de compreender no mundo presente os sentidos transdisciplinares de brinquedos e brincadeiras do Programa Território do Brincar, uma vez que os brinquedos e as brincadeiras permitiram aos sujeitos deste estudo, crianças de diversas regiões brasileiras, um transitar pelos diferentes níveis de realidade do objeto (os brinquedos e brincadeiras), considerando diferentes níveis de percepção e de 
consciência do sujeito transdisciplinar (a criança que brinca), na perspectiva da lógica do terceiro termo incluído que é caracterizadora da vivência da alteridade, a qual se manifesta em complexidade na integração do corpo, mente e espírito; na sensação de plenitude, prazer e bemestar; na circularidade, interatividade, recursividade, auto-organização, emergência e transcendência; na intuição, imaginação, sensibilidade, criatividade, dimensões constitutivas da inteireza humana que são possibilitadas pelo brincar.

Para Nicolescu (1999, p. 149), a transdisciplinaridade “[...] pressupõe uma racionalidade aberta a um novo olhar sobre a relatividade das noções de 'definição' e de 'objetividade'[...]". Neste estudo, tomou-se o brincar como um processo transdisciplinar, pois este é fruto de interações intra-subjetivas e intersubjetivas entre os sujeitos que brincam e promove a intuição, a imaginação, a sensibilidade e a criatividade. Para Canda, Soares e Zen (2018, p. 421) "os sentidos e significados da experiência do brincar só podem ser compartilhados por aqueles que de fato estão imersos nessa produção".

O brincar consiste numa dinâmica integradora entre os sujeitos que brincam, uma vez que permite a integração do corpo e da mente, unidos em um movimento de fruição, vivenciado pela sensação de plenitude, prazer e bem-estar. Esse movimento de fruição que no brincar implica a materialização de uma metodologia não linear que envolva circularidade, interatividade, recursividade e auto-organização entre os sujeitos que brincam, envolve diferentes níveis de realidade e, dessa forma, permite que o sujeito que brinca, aprenda em complexidade com outros sujeitos e, portanto, vivencie o dinamismo da alteridade. Para Frankiv e Domingues (2016, p. 123) " [...] o pensamento complexo analisa a importância da transdisciplinaridade, a fim de ser uma possibilidade de superação da dicotomia e da fragmentação". Ressalta-se que no ato de brincar, essa dicotomia e fragmentação são naturalmente superadas, pois ao brincar as crianças desenvolvem também algumas capacidades de socialização, por meio de interação e da utilização e experimentação de regras e papéis sociais que lhes permitem uma viver transdisciplinarmente.

O brincar produz interações intra-subjetivas e intersubjetivas entre os sujeitos e, desse modo, consiste numa ação transdisciplinar. O brincar se inscreve no que Nicolescu (1999) denomina de zona de não resistência, a qual pode ser penetrada pela intuição, da imaginação, da sensibilidade e da criatividade que são aspectos constitutivos da natureza humana.

Nicolescu (1999) afirma que a educação transdisciplinar é uma proposta da e para a libertação, uma vivência que permite e estimula a religação das pessoas, dos eventos e das pessoas aos eventos. Pode-se dizer que o brincar se alinha perfeitamente a essa ótica, pois ao 
brincar o sujeito se encontra com o outro. Ou seja, no ato de brincar eu e outrem comungamos sobre um mesmo panorama, embora o vejamos por diferentes níveis de realidade. No ato de brincar a minha perspectiva e a do outro são, assim, simultaneamente possíveis e, por isso, há a vivência da alteridade. Nesse sentido, é produzido, por meio do brincar, o diálogo entre os sujeitos, ou no dizer de Merleau-Ponty (1945, p. 41), “[...] há um entre-os-dois, eu e o outro somos colaboradores, numa reciprocidade perfeita coexistindo no mesmo mundo [...]".

Em síntese, pode-se dizer que a vivência da transdisciplinaridade no ato de brincar constitui uma tessitura complexa e relacional que é tecida nos interstícios e nas tramas próprias do ato de brincar, por meio de uma dinâmica complexa e, portanto, transdisciplinar.

\section{Uma análise transdisciplinar sobre brinquedos e brincadeiras do Programa Território do Brincar}

Neste item, procede-se a uma análise de vídeos documentários que retratam algumas brincadeiras de diferentes regiões do Brasil já referidas anteriormente neste texto. Reitera-se que essa análise foi realizada com base nos três pilares da metodologia transdisciplinar proposta por Nicolescu, ou seja, os diferentes níveis de realidade, a lógica do terceiro termo incluído e a complexidade.

Nos diferentes níveis de realidade, processa-se o entendimento da realidade como um processo dinâmico, em contínua interação. E, nesse sentido, a análise de brinquedos e brincadeiras do Programa Território do Brincar neste estudo, buscou identificar no ato de brincar das crianças, esse processo dinâmico e a contínua interação das crianças por meio do brincar.

Com relação à lógica do terceiro termo incluído, segundo Santos; Santos e Chiquieri (2009) é admitida uma interação entre opostos e se interpõem conhecimentos concebidos através dos diversos saberes que se situam entre os saberes e se projetam além dos saberes constituídos. Essa lógica "[...] implica a impossibilidade de uma teoria completa, fechada em si mesma [...]" (Ibid., p.8). Nesse sentido, o conhecimento deve ser construído por meio de aprendizagens coletivas que deverão acontecer pela vivência da alteridade que no caso desta investigação, esteve focada no ato de brincar. Por isso, para esta análise foram considerados alguns aspectos que induzem à lógica do terceiro termo incluído por permitirem a vivência da alteridade que se materializa nas brincadeiras retratadas nos vídeos documentários do Programa Território do Brincar, por meio da integração entre as crianças, do prazer e bem-estar, da 
interatividade, da imaginação, da sensibilidade e da criatividade presentes nas brincadeiras objeto de análise.

Os brinquedos e as brincadeiras retratados nos vídeos documentários do Programa Território do Brincar rompem com uma lógica binária e fragmentadora do conhecimento e promovem vivências e aprendizagens transdisciplinares entre as crianças que brincam evidenciando, dessa forma, a consubstanciação da alteridade uma vez que no brincar das crianças, há respeito pelo pensamento do outro que embora seja por vezes diferente, é legítimo. E, nesse sentido, observa-se nesse âmbito, a materialização da lógica do terceiro termo incluído que reafirma a vivência da transdisciplinaridade no ato de brincar.

Sobre a complexidade, afirmam Santos; Santos e Chiquieri (2009, p.10) que esta, “[...] na sistematização de Morin (1991), transforma-se em um princípio fundamental: princípio Unitas Multiplex [...]”. Em outras palavras, mas ainda na opinião dos autores supracitados, isto quer dizer "[...] unidade na diversidade ou unidade múltipla, conforme a formalização da lógica do terceiro termo incluído [...]" (Ibid., p. 10). Sendo assim, ao analisar os brinquedos e as brincadeiras retratados nos vídeos documentários do Programa Território do Brincar, tendo por base a vivência da Complexidade entre as crianças, perquiriu-se no âmbito das brincadeiras a unidade na diversidade ou a unidade múltipla.

Desse modo, é de referir que para a análise a seguir sobre vivências transdisciplinares por meio de brinquedos e brincadeiras do Programa Território do Brincar procede-se, inicialmente, a um relato das brincadeiras em que são destacadas as falas das crianças que brincam e, em seguida, procura-se identificar nos gestos e expressões das crianças a vivência da transdisciplinaridade referentes aos diferentes níveis de realidade, à lógica do terceiro termo incluído e à complexidade.

\subsection{Vivências transdisciplinares na brincadeira de palmas}

Neste item procede-se a uma descrição e análise da brincadeira de palmas. Segundo o Programa Território do Brincar (2016), as brincadeiras de palmas acontecem a qualquer hora. É uma brincadeira que acontece de forma rimada e alegre. O desafio quase sempre é coordenar as palmas e os cantos.

\subsubsection{Descrição da brincadeira de palmas}

A brincadeira de palmas nas diversas regiões do Brasil se inicia no Córrego da Velha de Baixo em Minas Gerais. Observam-se três meninas brincando de palmas. Quando acaba a 
brincadeira, uma delas explica o que vão fazer a seguir e diz: “ai nós sai (sic) correndo e ela tem de falar uma cor uma cor e nós vai (sic) correr pra pegar na cor. Se ela correr e alcançar nós aí nós perde, aí ela pega e ganha”.E continua explicando: "Se nós duas conseguir pegar na cor, ela vai e perde. Daí ela pegar nós antes de nós chegar na cor, aí ela pega e ganha. Vocês entenderam?"

Em outra cena, aparecem quatro meninas brincando de palmas na cidade de Acupe, Bahia. Elas batem palmas e cantam: "loira, morena, careca, cabeluda, rainha, ladrona, polícia, capitã”. Em seguida, aparecem em outra cena cinco meninas que sorriem muito e batem palmas, cuja brincadeira de palmas consiste na exclusão de quem perde. Na sequência, aparecem duas meninas que batem palmas e a seguir ficam em posição de estátuas. No seguimento, o vídeo mostra a brincadeira de palmas na cidade de Tatajuba, Ceará, entre duas meninas que cantam e batem palmas de forma integrada.

\subsubsection{Uma análise da brincadeira de palmas}

Observa-se na brincadeira de palmas, a presença de diferentes níveis de realidade, uma vez que a mesma é apresentada em diversas regiões brasileiras e registram diferentes percepções das crianças que brincam sobre uma mesma brincadeira. Nesse sentido, evidenciase nessa brincadeira o pilar diferentes níveis de realidade, proposto por Nicolescu (1999), no âmbito da metodologia transdisciplinar. Sobre esses diferentes níveis de realidade na brincadeira de palmas, registramos diferentes vivências e convivências. Assim, em Minas Gerais, uma das meninas que brinca explica a brincadeira dizendo: "Ai nós sai correndo e ela tem de falar uma cor e nós vai (sic) correr pra pegar na cor. Se ela correr a alcançar nós, aí nós perde, aí ela pega e ganha. Se nós duas conseguiu pegar na cor, ela vai e perde. Daí ela pegar nós antes de nós chegar na cor, aí ela pega e ganha”. Observe-se que há nesse fragmento de discurso evidências da presença da lógica de um terceiro termo incluído, pois se percebe no discurso da menina que relata a brincadeira de palmas, em Minas Gerais, um respeito ao pensamento do outro, além de uma interatividade, prazer, bem-estar e criatividade que são indícios da materialização desse pilar da metodologia transdisciplinar proposta por Nicolescu, quando ela refere: "ai nós sai correndo e ela tem de falar uma cor e nós vai (sic) correr pra pegar na cor. Se ela correr a alcançar nós, ai nós perde, ai ela pega e ganha[...]”. Neste fragmento de discurso há uma integração entre as meninas que brincam para que o objetivo da brincadeira seja alcançado, "pegar na cor”. Note-se ainda, na diversidade uma unidade múltipla entre as meninas que brincam que indica a vivência da complexidade, a qual constitui outro 
pilar da metodologia transdisciplinar, pois embora elas estejam a competir entre si, compõem uma unidade múltipla, isto é, para realizar a brincadeira há uma unidade entre opostos.

É ainda de registrar uma polissemia dos símbolos, emoções, sentimentos e afetos no ato de brincar em outras regiões brasileiras, como por exemplo, numa cena em que aparecem quatro meninas brincando de palmas na cidade de Acupe, Bahia. Elas batem palmas e cantam: “loira, morena, careca, cabeluda, rainha, ladrona, polícia, capitã”. Em seguida, aparecem em outra cena, também em Acupe, Bahia, cinco meninas que sorriem muito e batem palmas. Nessa última cena, a brincadeira de palmas consiste na exclusão de quem perde. Estas duas cenas remetem de certa forma, aos três pilares da metodologia transdisciplinar que, nesse caso, são materializados pela interatividade, respeito ao pensamento do outro e pela conjugação de esforços no sentido de distinguir sem separar e associar sem reduzir por meio do princípio dialógico, o que leva as crianças a atuarem e pensarem em complexidade, inclusive, numa cena que acontece em seguida em que aparecem duas meninas que batem palmas e a seguir ficam em posição de estátuas. A posição adotada pelas duas meninas que nessa cena também brincam de palmas, revela uma interlocução entre elas. Por fim, registra-se a última brincadeira de palmas na cidade de Tatajuba, Ceará, entre duas meninas que cantam e batem palmas também de forma integrada, demonstrando respeito ao pensamento do outro.

Em síntese, pode-se dizer que a transdiciplinaridade na brincadeira de palmas aqui analisada, é vivenciada sob a égide dos três pilares da metodologia transdisciplinar proposta por Nicolescu, pois para além de promover a vivência da alteridade, que é um dinamismo potencializador da lógica do terceiro termo incluído, acontecem em diversos níveis de realidade pela conjugação de esforços por meio do princípio dialógico que remete à complexidade.

\subsection{Vivências transdisciplinares na brincadeira pião de biorra}

Segundo o Programa Território do Brincar (2016), Biorra é um fruto que só macaco e pássaro comem. A primeira vista parece um abacate verde novinho. A vareta tem que ser reta, é o eixo do pião. Fazer o pião não parar de rodar é o grande desafio dessa brincadeira que será a seguir descrita e analisada.

\subsubsection{Descrição da brincadeira de pião de biorra}

A brincadeira pião de biorra ocorre em Abadia, Minas Gerais. No início do vídeo, aparecem imagens de um cavalo e um homem com um periquito no ombro e dois homens conversando em frente a uma casa. Aparecem ainda, dois meninos que estão correndo 
próximasàs casas da zona rural, duas meninas pulando em um rio e um homem cavalgando pela cidade. Após essas cenas um menino fala: “Aqui em Abadia tem muitas pessoas, crianças, tem um monte de coisas, tem um rio e biorra". Logo depois aparece um grupo de três meninas em uma área rural que atravessam uma cerca com arames para pegar a biorra. Após passarem pela cerca, chegam ao pé de biorra e colhem o fruto e uma menina fala: "Lá tem um pé de biorra, biorra” (MENINA 1); “Achei uma grandinha” (MENINA 2) (Risadas).

Após colherem o fruto, as meninas caminham em direção a uma casa. Uma delas levanta o arame da cerca para suas colegas passarem. Em seguida, se juntam no quintal com outras crianças e começam a preparar a biorra para fazerem o pião. Utilizam uma faca para descascar a parte superior e inferior do fruto e dizem: “Odaléa, é assim que começa?" (MENINA 3). “A gente tem que começar assim Tati, cortando assim, ô!.” (MENINA 4). Após essa cena, um dos meninos utiliza uma faca para descascar a parte superior e inferior do fruto. É tipo uma bolinha assim. "Aí, a verde a gente vai e corta em cima e embaixo. Aí a gente vai e coloca o bambu e vai e coloca e roda." (MENINO 1)

Logo depois, raspam um pedaço de bambu e espetam no fruto. Limpam o chão com a mão preparando-se para a brincadeira. Após esses procedimentos, começam a brincar com o pião que construíram e se expressam durante a brincadeira da seguinte forma: "Quando você vê que ela está indo mais devagar, você vai [...]” ( MENINO 2). E, nesse momento, o menino roda o palito de bambu com mais força, mostrando como se faz para rodar o pião mais rápido. O Menino 3 diz: “a minha tá sem gasulina (sic)”. E, assim, as crianças produzem onomatopéias para imitar sons de velocidade e intensidade ao rodar o pião de biorra.

\subsubsection{Uma análise da brincadeira pião de biorra}

Uma análise da brincadeira pião de biorra, permite dizer que há uma vivência de diferentes níveis de realidade, um dos pilares da metodologia transdisciplinar proposta por Nicolescu (1999), quando uma das meninas interage com outra de idade menor indicando o procedimento adequado para construir o Pião de Biorra e fala: “a gente tem que começar assim Tati, cortando assim, $\hat{o}$ !”. A fala da menina indica uma abertura e o não fechamento à percepção que possui sobre a brincadeira, mesmo estando com níveis de conhecimento e realidade diferentes ao da colega.

Os diferentes níveis de realidade presentes na brincadeira objeto desta análise incidem também na interatividade visivelmente construída quando uma das meninas mostra a maneira de proceder para a construção do brinquedo e um menino acrescenta: “[...] a gente vai e corta 
em cima e embaixo. Aí a gente vai e coloca o bambu e vai e coloca e roda". Os discursos das crianças remetem a uma necessidade de interação entre eles e uma abertura para a interação de diferentes percepções sobre a construção do brinquedo. Ou seja, há diferentes vivências e aprendizagens num processo dinâmico e uma contínua interação por meio do brincar.

Ainda com base nos trechos dos discursos das crianças, identificou-se a presença da lógica do terceiro termo incluído na brincadeira, pois na construção dessa brincadeira observase um respeito ao pensamento do outro. Esse respeito é notório quando a menina mostra a maneira de proceder para a construção do pião e o menino acrescenta informações ao pensamento dela, por meio de seus saberes. $\mathrm{O}$ discurso ainda remete a uma sensibilidade de escuta às necessidades e ao conhecimento do outro criando interfaces complementares para a construção do brinquedo. Registram-se, nessa brincadeira, ações que possibilitam às crianças o estímulo da criatividade, pois as cenas presentes no vídeo mostram crianças transformando frutos em brinquedos.

Há ainda uma vivência transdisciplinar da brincadeira pião de biorra alusiva à lógica do terceiro termo incluído quando com uma faca, as crianças descascam a parte superior e inferior da biorra, raspam um pedaço de bambu e o espetam no fruto, limpam o chão com a mão e, juntas, compartilham o prazer em brincar com um brinquedo construído por elas. Nesse sentido, produzem onomatopéias para imitarem sons de velocidade e intensidade ao rodar o pião de biorra. Nessa ação, há integração entre as crianças, prazer e bem-estar, interatividade, imaginação, sensibilidade e criatividade que constituem aspectos inerentes à lógica do terceiro termo incluído.

Em suma, conclui-se que com essa brincadeira as crianças vivenciaram diversas interlocuções e, por meio de uma relação dialógica, expressaram o prazer na construção do brinquedo, o pião de biorra, e atribuíram sentidos transdisciplinares ao ato de brincar. Esses sentidos podem ser entendidos pelo transitar das crianças por diferentes níveis de realidade do objeto, o pião de biorra. A ação das crianças na construção da brincadeira em questão, écaracterizadora de um terceiro dinamismo que revela outras vivências transdisciplinares inerentes à lógica do terceiro incluído.

\subsection{Vivências transdisciplinares na brincadeira pista com meninos}

Relata o Programa Território do Brincar (2016) que a brincadeira pistas com meninos, surge do encontro de meninos de idades diferentes e desejos iguais. Nesse sentido, refere o 
programa objeto desta análise que o "Vitor se encarregou de buscar os pauzinhos e o Luiz Fernando trouxe o caco de telha, riscaram o chão e a pista ficou pronta em menos de três minutos, já com os carrinhos (tampinhas de garrafa) a postos para a partida”.

\subsubsection{Descrição da brincadeira pista com meninos}

A brincadeira pista com meninos acontece em Acupe, Bahia. De início, o vídeo apresenta a comunidade onde vivem as crianças. Mostra casas da zona rural e, em seguida, um menino apresenta-se dizendo: "você mora onde? Em Acupe, está muito calor”. Esta pergunta é de um dos meninos que é respondida por ele mesmo a si. Logo, os meninos iniciam a brincadeira. Nessa brincadeira, eles desenham no chão de terra com uma telha uma pista na terra. Desenham uma pista arrastando a telha pelo chão e, em seguida, com a mesma telha eles marcam os obstáculos na estrada que foi desenhada. Fazem lombadas para que a construção tenha feição de uma pista. Na sequência, para simular um carro, eles utilizam uma tampa de garrafa e brincam com ela. Assim, os meninos discutem sobre as regras da brincadeira e nesse momento um dos meninos (MENINO 1) diz: "na linha olhe, vá você também.” O Menino 2 diz: "ai é outra pista”. Nesse momento, o Menino 1 responde: "mas é na mesma pista aí rapaz, na mesma pista aqui ó...”. O Menino 2 ri do Menino 1 por não ter conseguido avançar com a tampinha e o Menino 1 diz: "eu vou ficar por aqui mesmo”. O Menino 2 diz: "tchau Mundinho”. Os demais meninos continuam a brincadeira.

\subsubsection{Uma análise da brincadeira pista com meninos}

$\mathrm{Na}$ brincadeira pista com meninos, foi possível registrar algumas vivências transdisciplinares relacionadas à lógica do terceiro termo incluído, a qual foi materializada pela integração entre as crianças, interatividade, imaginação, sensibilidade e criatividade, nomeadamente quando os meninos desenham com uma telha uma pista na terra que vai servir de locus para a brincadeira. As cenas da construção da pista e depois da simulação de um carro (a tampa de garrafa) na pista remetem à vivência de ações prazerosas e integradas, em que as crianças reconstroem cenas do real, recriam objetos, demarcam espaços e interagem em suas percepções sobre a maneira de construir o espaço para a realização da brincadeira. Evidenciase a compreensão de mundo pelos meninos quando, por meio da criatividade e imaginação, eles 
recriam elementos do cenário real dando sentido à brincadeira. Essa construção dialogada entre os meninos denota também respeito ao pensamento do outro.

Verifica-se ainda na referida brincadeira, sentidos transdisciplinares concernentes à complexidade, uma vez que há uma unidade na diversidade e uma unidade múltipla quando as crianças discutem as regras da brincadeira e interagem. Sobre as regras da brincadeira, o Menino 1 afirma: "na linha olhe, vá você também". Já o Menino 2 diz: "aí é outra pista;". E logo o Menino 1 questiona a regra da brincadeira responde: "mas é na mesma pista aí rapaz, na mesma pista aqui ó...”. O Menino 2 ri do seu colega por não ter conseguido avançar com a tampinha e o Menino 1 diz: "eи vou ficar por aqui mesmo". Os discursos dos meninos são interativos, apesar de existirem posturas e pensamentos opostos. A postura oposta entre os meninos é manifestada na diversidade de saberes, ou seja, cada menino possui diferentes vivências. No entanto, há uma construção dialógica que se estabelece por vias opostas em busca de uma unidade que é a realização da brincadeira e do prazer vivenciado pelos meninos no desenvolvimento dela.

Consoante à presença da complexidade na brincadeira há, também, a presença de diferentes níveis de realidade, uma vez que se observa um processo dinâmico e uma contínua interação das crianças no ato de brincar. Verificou-se ainda, que os meninos tomam decisões conjuntas para a construção da pista de areia e sobre as regras estabelecidas para a brincadeira. Apesar de possuírem idades e tamanhos diferentes, os meninos interagem compartilhando vivências, alegrias e a busca de papéis sociais dos que não são vividos cotidianamente.

Em síntese, conclui-se que na brincadeira pista com meninos as vivências transdisciplinares se materializam pelos três pilares da metodologia transdisciplinar que se constituíram no âmbito deste estudo em dimensões de análise, pois embora os meninos aparentem ter posturas opostas, se inserem no que Nicolescu (1999) chama de zona de não resistência, ou zona do Sagrado. A zona do Sagrado, no que diz respeito ao brincar, é constituída pela intuição, imaginação, sensibilidade e criatividade, que são aspectos constitutivos da inteireza humana e da vivência da transdisciplinaridade.

\subsection{Vivências transdisciplinares na brincadeira boi de pedra}

Segundo o Programa Território do Brincar (2016), o boi é peça chave do brincar no Sertão do Ceará. O boi de pedra é uma criação das crianças que dizem que pegaram umas pedras parecidas com o boi e as transformaram em bois. 
4.4.1 Descrição da brincadeira boi de pedra

No início do vídeo aparece um desenho de um boi numa grande pedra onde está escrito: "boi de pedra". O vídeo foi feito numa comunidade rural, onde aparecem animais passando pelos caminhos e bastante capim no solo. Observa-se um homem andando em um burro e tangendo os bois. Logo em seguida, observam-se quatro crianças retratando a cena descrita anteriormente. As crianças andam de cócoras, "tangendo" os bois que são feitos de pedras. $\mathrm{Na}$ apresentação do vídeo aparece a voz de uma pessoa adulta que diz: "o boi é peça chave no brincar do Sertão do Ceará”. Após essa fala um menino, aqui denominado de MENINO 1 diz: "é que desde pequeno, nós ia deixar o gado, aí como a gente gostava muito, aí nós inventemos (sic) o boi de pedra, peguemos, vimos assim umas pedras assim parecido com um boi, aí nós começamos a brincar". Na sequência, outro menino, o MENINO 2, diz: “aqui é os dois bezerros, aqui é um garrote e isso aqui é o boi", e o menino 1 diz: "abre a porteira boi”. A voz de uma pessoa adulta faz a narrativa da cena dizendo: "o menino vaqueiro gruda-se ao chão, reproduzindo a vida como ela é”. Os meninos seguem utilizando os bois (pedras) para brincar e utilizam a imaginação e o faz de conta para retratarem sua cultura e vivências. Seguindo a narrativa, a voz de uma pessoa adulta diz: "o chão é sabedor de verdades, a brincadeira também".

Os meninos continuam a brincadeira e o Menino 1 diz: "as vezes tem casamento, a gente pega, aí amarra no mourão, ai mata, parte os pedaços, aí faz o casamento”. O Menino 2 prossegue dizendo: "vamos matar, vamos matar, dá logo com força pra matar de uma vez". Para isso, as crianças amarram uma pedra com um cordão e prendem a um pedaço de pau usando a imaginação como se estivessem matando o boi. O Menino 2 diz: "partir o boi. $O$ boi tava gordo viu? A carne tá dura porque o boi é velho... isso tudo é carne!" (fala mostrando os pedaços de pedras partidos dentro de um recipiente). O Menino 3, então, diz: "botar lenha no fogão...", e o Menino 2 prossegue dizendo: "bora, senão a carne estraga..."

Logo, eles colocam os pedaços de pedras dentro de quengas de coco para simular que estão no fogo, o fogo é feito por um tijolo de furos e então mexem a "carne", dizendo: "mexer a carne, senão ela não presta". A voz de uma pessoa adulta que narra a cena diz: "fazem de conta que viver e brincar, são tudo a mesma coisa".

$\mathrm{Na}$ sequência, o Menino 4 informa: "começou o casamento e a noiva não chegou”. Organizam as mesas dizendo: “aqui é a da família do fazendeiro". Isso numa "mesa" feita por um tijolo de furos e pedaços de espeto de pau simulando as cadeiras. Ao lado dizem que é a mesa da família deles: "minha tia, minha mãe, meu pai”. Continuando a brincadeira o 
Menino 5 diz: "tá chegando lá vem ela ali no portão, olhe...”. E, para a "realização do casamento" o Menino 2 pergunta: "Senhora Josefina, aceita o senhor Geraldo como seu legítimo esposo?”, ao que o Menino 5 responde: “claro que sim”. E, assim, o Menino 2 diz: "então vos declaro marido e mulher. O noivo pode beijar a noiva. Aí pode servir agora, pode servir a comida pros convidados”. E conclui-se a brincadeira.

\subsubsection{Uma análise da brincadeira boi de pedra}

Pode-se afirmar que há na brincadeira boi de pedra, vivências transdisciplinares que são evidenciados por processos interdependentes e constituídos em rede, os quais envolvem aspectos interativos, recursivos, dialógicos, construtivos, socioafetivo e culturais. Esses elementos inerentes à vivência da transdisciplinaridade podem ser identificados na brincadeira objeto desta análise se olharmos para os diferentes níveis de realidade que emergem quando as crianças respeitam as diferentes vivências e percepções dos colegas. Um exemplo disso está no brincar conjunto das crianças e na contribuição de todas para a mesma brincadeira. Convém ressaltar, a polissemia dos símbolos que é sinalizadora de diferentes níveis de realidades expressa no faz de conta das crianças nos seguintes discursos: Menino 2: “vamos matar, vamos matar, dá logo com força pra matar de uma vez”. Para isso as crianças amarram uma pedra com um cordão e prendem a um pedaço de pau e usam a imaginação como se estivessem matando o boi. Menino 2: "partir o boi. O boi tava gordo viu? A carne tá dura porque o boi é velho... isso tudo é carne!" (fala mostrando os pedaços de pedras partidos dentro de um recipiente). Ressaltam-se ainda, os seguintes discursos que se inserem numa polissemia de símbolos caracterizadora de diferentes realidades: Menino 3: "botar lenha no fogão...”; Menino 2: "borá, senão a carne estraga...”; Menino 4: “começou o casamento e a noiva não chegou"; Menino 5: "tá chegando lá vem ela ali no portão, olhe...”; Menino 2: "Senhora Josefina, aceita o senhor Geraldo como seu legítimo esposo?”; Menino 5: “claro que sim”; Menino 2: "então vos declaro marido e mulher, o noivo pode beijar a noiva. Ai pode servir agora, pode servir a comida pros convidados".

Há nos discursos das crianças acima transcritos, uma travessia de fronteiras, uma criação permanente e uma aceitação do diferente. Essa vivência transdisciplinar das crianças nessa brincadeira faz com que elas criem um conhecimento novo, por meio de um processo intersubjetivo em sinergia, que envolve diferentes dimensões humanas pela conjugação de esforços. Observe-se, pois, essa conjugação de esforços quando o Menino 2 diz: "vamos matar, 
vamos matar, dá logo com força pra matar de uma vez”. Nesse discurso do Menino 2 a conjugação de esforços segue um processo dialógico, próprio do pensamento transdisciplinar que transcende a lógica binária fragmentadora da realidade. Identifica-se no diálogo das crianças uma complementaridade das polaridades aparentemente contrárias que ajuda a promoção da alteridade entre essas crianças que brincam. Enfim, pode-se dizer que na brincadeira boi de pedraa transdisciplinaridade acontece "entre", "além" e "através" das situações vivenciadas pelas crianças.

\subsection{Vivências transdisciplinares na brincadeira batizado de bonecas}

Segundo o Programa Território do Brincar (2016), em Abadia, Minas Gerais, as crianças fazem bonecas de certo tufo de capim. A confecção começa pelo cabelo e o corpo vem depois, com retalhos amarrados e fitas no cabelo. Aprontadas as bonecas, é hora de organizar o altar, preparar o padre, padrinhos, pais e a água batismal.

\subsubsection{Descrição da brincadeira batizado de bonecas}

A brincadeira batizado de bonecas acontece em Abadia, Minas Gerais. A brincadeira acontece na zona rural do município de Abadia, onde as crianças colhem no mato o que irão utilizar para produzir a boneca e uma das meninas diz: "buscar bonequinha no mato, fazer batizado”. As crianças vão ao mato pegar capim para iniciar a produção da boneca, produzindo de início a cabeça. As folhas formam os cabelos e o barro será a cabeça. Depois de confeccionar as bonecas, as crianças cobrem com um pano o corpo das bonecas para poder prosseguirem com o batizado.

Na cena seguinte, as crianças assumem os papéis de mãe, padre e madrinhas e, nesse momento, o "padre" diz: "estamos aqui hoje para realizar o batismo dessa menina, e agora vocês vão dizer: renuncio. Vocês renunciam que essa menina é, será sempre no caminho de Jesus"?e a "mãe" e "madrinhas" respondem: "renuncio". O "padre" diz: vocês creem na paz do senhor? E a "mãe e madrinhas" respondem: "creio". O "padre" prossegue: "estamos aqui reunidos para realizar o batizado da Isabela e Vitória. As duas gêmeas." O "padre” pergunta: “elas têm registro?” e a "mãe" responde: “tem”. O "padre” prossegue: “agora vamos despejar água benta para dizer que elas estão sempre com Jesus. " Em seguida o "padre” coloca a água benta na cabeça das bonecas e considera-as batizadas. A "mãe" diz: "batizamos a minha filha". E assim, conclui-se a brincadeira. 
4.5.2 Uma análise da brincadeira batizado de bonecas

$\mathrm{Na}$ brincadeira batizado de bonecas verifica-se que as crianças, integradas pelo prazer em brincar, colhem no mato o material para a construção do brinquedo. Uma menina em companhia de outras crianças afirma que vai “buscar bonequinha no mato”. Essa fala simboliza um bem estar individual que transpassa o coletivo, pois ir à busca da bonequinha é envolver-se em emoções e encontrar-se com o contentamento.

Pode-se dizer que a lógica do terceiro termo incluído está presente nessa brincadeira, se considerarmos a integração e o prazer que as crianças demonstram na busca da bonequinha e no processo de coleta do material, pois nessa ação há uma integração de diferentes esforços para a vivência de uma ação comum, por meio da simulação de ações do mundo real no universo da brincadeira das crianças. Ressaltam-se vivências transdisciplinares na brincadeira em questão pelo exercício de criar e recriar que as crianças promovem com elementos do cotidiano, por meio da imaginação e do estabelecimento de sentidos ao brinquedo criado, uma vez que as meninas que brincam experimentam diferentes papéis sociais como, por exemplo: padre, madrinha, padrinho, mãe e filha. A vivência desses papéis sociais na brincadeira batizado de boneca, é fundamentada pela imaginação e criatividade infantil que permitem a reconstrução de ações reais, ou seja, a integração entre as crianças, no prazer e bem-estar.

$\mathrm{Na}$ brincadeira batizado de bonecas há, também, a presença de diferentes níveis de realidade, uma vez que as crianças, durante a brincadeira, estão inseridas num processo dinâmico e em contínua interação. Isso é notório quando o "padre" afirma: "estamos aqui hoje para realizar o batismo dessa menina" e questiona: "vocês creem na paz do senhor?" As crianças que estão representando a mãe e as madrinhas dizem: “creio”. O “padre” prossegue o batismo afirmando: "estamos aqui reunidos para realizar o batizado da Isabela e Vitória. As duas gêmeas". Ele pergunta: "elas têm registro"? A “mãe" responde: "tem”. Com base nesses trechos dos discursos das crianças, verifica-se que durante a brincadeira elas estavam em constante interação simulando ações do cotidiano no universo do brincar.

Verifica-se ainda na referida brincadeira, a presença da complexidade. Ou seja, da conjugação de esforços no sentido de distinguir sem separar. Isso é evidenciado quando o “padre” pergunta: “vocês renunciam que essa menina, será sempre no caminho de Jesus?” E a "mãe" e as "madrinhas" respondem: "renuncio". O fato de a mãe e as madrinhas afirmarem que a menina andará pelos caminhos de Jesus, remete uma unidade múltipla um intercâmbio de pensamentos, apesar de estarem em papéis sociais diferentes. As crianças buscam aglutinar 
esforços, integrando conhecimentos e atribuindo sentido à brincadeira à maneira como nela atuam.

Em suma, pode-se dizer que a brincadeira batizado de bonecas, é construída por uma lógica ternária (lógica do terceiro termo incluído), uma vez que possibilita em todo o processo, a inclusão de um terceiro dinamismo energético ou de uma interatividade entre as crianças.

\subsection{Vivências transdisciplinares na brincadeira casinhas no Vale do Jequitinhonha}

A brincadeira casinhas no Vale do Jequitinhonha acontece no Vale Jequitinhonha, Minas Gerais. A brincadeira se dá na zona rural do Estado, com crianças já mais crescidas.

\subsubsection{Descrição da brincadeira casinhas do Vale do Jequitinhonha}

No início do vídeo, ouvem-se vozes das crianças a prepararem, em conjunto, o terreno para a construção das casinhas. Essa construção é feita por crianças mais crescidas e, por isso, a produção das casas se dá de forma mais complexa. Nesse sentido, as crianças limpam o terreno onde serão montadas as casinhas. Os meninos montam os paus e as cortinas para erguerem as casas e, em seguida, as meninas fazem a decoração das casas com objetos pequenos coloridos pendurados em barbante. Elas montam camas com pedaços de pau e panos, que seriam para as bonecas dormirem. Adaptam uma mesa no chão forrando-a com pano e dispondo sobre ela talheres e pratos de brinquedo. Vestem as bonecas com tecidos e as colocam para dormir. Um dos meninos faz uma fogueira simulando o fogo para esquentar as casas. Em seguida, produzem cavalos de pau para carregar os objetos de suas necessidades. Produzem, também, um fogão a lenha com tijolos e simulam a comida com bolinhos de barro nos pratos de brinquedo, colhem matos, frutos, folhas na natureza e põem para cozinhar no fogão de tijolos produzido por eles. Nesse momento, uma das crianças diz: "é feijoada”!

As crianças fazem a decoração dos pratos com flores colhidas na natureza. Em seguida, uma das crianças pergunta ao produtor do vídeo: “quer café?” e acrescenta: "tome, pegue sua caneca”. O café é feito com água de barro. E assim, as crianças continuam a brincadeira de casinhas e conclui-se o vídeo documentário.

\subsubsection{Uma análise da brincadeira casinhas do Vale do Jequitinhonha}

Na brincadeira casinhas do Vale do Jequitinhonha, observam-se algumas vivências transdisciplinares que são geradas por uma dinâmica integradora, na qual estão entrelaçadas 
várias dimensões humanas em total integração do corpo, mente e espírito, unidos em um movimento de fruição que é vivenciado pelas crianças pela sensação de plenitude, prazer e bemestar que são caracterizadores da transdisciplinaridade na perspectiva da lógica do terceiro termo incluído, dos diferentes níveis de realidade e da complexidade.

Com relação à vivência da transdisciplinaridade na perspectiva da lógica do terceiro termo incluído na brincadeira de casinhas do Vale do Jequitinhonha, verifica-se que as crianças respeitam o pensamento do outro, integram ações, reconstroem objetos, interagem pelo prazer de brincar. As crianças compartilham na brincadeira um "lugar" para o imaginário, o emocional, os sentimentos, o sensível e a vivência de suas fantasias.

A vivência da transdisciplinaridade na referida brincadeira sob a perspectiva de diferentes níveis de realidade acontece, por meio de um processo dinâmico e de interações intrasubjetivas e intersubjetivas e da recursividade que é denotada, por exemplo, no discurso das crianças quando uma delas afirma: "é feijoada" e, em seguida, outra criança pergunta a uma pessoa da produção do vídeo: "quer café? Tome, pegue sua caneca”. Esses discursos indicam que essas interações lhes oportunizaram criar e reinventar situações num processo de faz de conta. Ou seja, há nesse processo o verdadeiro se une à brincadeira pelo faz de conta, o que possibilita às crianças uma sensação de plenitude, prazer e bem-estar.

É de notar ainda na brincadeira objeto desta análise uma unidade múltipla, quando meninas e meninos, se empenham na construção das casinhas. As crianças conjugam esforços, por meio do princípio dialógico. Há uma distinção de ações, uma vez que meninos e meninas se encarregam de várias distintas que são realizadas pela conjugação de esforços em que meninos montam as casas com madeiras e fazem fogueira e as meninas, arrumam, decoram, limpam e juntas cozinham, montam cama com tijolos. As crianças nessas cenas descritas procuram, na diversidade de ações, a unidade que é a vivência e o prazer em brincar, os quais traduzem vivências transdisciplinares.

\section{Considerações finais}

Tem-se por base destas considerações finais o que foi enunciado no início deste texto quando se afirmou que este artigo pretendeu apresentar resultados de uma pesquisa acadêmica que teve por objetivo investigar vivências transdisciplinares, por meio de brinquedos e brincadeiras registrados em vídeos documentários do Programa Território do Brincar. É, portanto, nessa perspectiva que nesta parte deste artigo pretende-se reafirmar alguns pontos que aqui serviram como objeto de reflexão e análise. 
Assim sendo, evidenciam-se nestas considerações finais reflexões decorrentes da análise das brincadeiras de palmas, pião de biorra, pista com meninos, boi de pedra, batizado de bonecas e casinhas do Vale do Jequitinhonha. Ou seja, ressalta-se nesta parte deste artigo a vivência dos três pilares da metodologia transdisciplinar proposta por Nicolescu, isto é, a vivência da alteridade, a lógica do terceiro termo incluído e a complexidade. Nesse sentido, foram identificadas nas brincadeiras analisadas diversas interlocuções, por meio de uma relação dialógica, pois embora as crianças no ato de brincar, por vezes, aparentem ter posturas opostas, se inseriram no que Nicolescu (1999) chama de zona de não resistência, ou zona do Sagrado. E, no que diz respeito a esta investigação, a zona do Sagrado foi constituída pela intuição, imaginação, sensibilidade e criatividade, que são aspectos constitutivos da inteireza humana e da vivência da transdisciplinaridade, revelados pelas crianças no ato do brincar.

Ressalta-se que as brincadeiras de palmas, pião de biorra, pista com meninos, boi de pedra, batizado de bonecas e casinhas do Vale do Jequitinhonha, propiciaram a vivência da transdisciplinaridade às criança pelo ato de brincar, pois se identificou no desenvolvimento das brincadeiras, uma lógica ternária que possibilitou a inclusão de um terceiro dinamismo energético que foi possível, principalmente, pela interatividade entre as crianças. A lógica ternária identificada no âmbito das brincadeiras analisadas sinalizou para a vivência do dinamismo da alteridade, por meio da conjugação de esforços, entre as crianças e adultos, pelo princípio dialógico.

Reitera-se que por meio da vivência da alteridade as crianças e adultos presentes nas brincadeiras que serviram de objeto para as reflexões aqui esboçadas, evidenciaram vivências transdisciplinares que foram materializadas pela vivência da lógica do terceiro termo incluído, principalmente, ao respeito ao pensamento do outro que nesse caso, aponta para prática da alteridade no ato de brincar. As vivências transdisciplinares também foram evidenciadas nas brincadeiras analisadas em diferentes níveis de realidade, identificadas nas percepções dos sujeitos (as crianças e os adultos que brincam), por meio de distintas vivências e convivências. Ainda registrou-se nas brincadeiras analisadas a conjugação de esforços no sentido de distinguir sem separar e associar sem reduzir que remete para outro pilar da metodologia transdisciplinar, a complexidade, a qual aponta também para outras vivências transdisciplinares nas brincadeiras que serviram de objeto de análise neste estudo, ou seja, o registro da complexidade nessas brincadeiras sinaliza para a dialogicidade que é fundamental a qualquer vivência transdisciplinar. 
Enfim, os resultados permitiram concluir que os brinquedos e as brincadeiras analisadas proporcionaram às crianças e aos adultos, vivências transdisciplinares na perspectiva da alteridade, ao respeito ao pensamento do outro (lógica do terceiro termo incluído). Identificou-se, também, uma polissemia dos símbolos e diferentes vivências, convivências e aprendizagens (diferentes níveis de realidade) e uma conjugação de esforços no ato de brincar por meio do princípio dialógico (complexidade).

\section{REFERÊNCIAS}

CANDA, Cilene Nascimento; SOARES, Leila da Franca; ZEN, Giovana Cristina. Vozes, Sentidos e Experiências na Extensão Universitária: o que dizem as crianças sobre o Brincar. Práxis Educacional, Vitória da Conquista - Bahia - Brasil, v. 14 n. 30, p. 415-435, out./dez. 2018. Disponível em: http://periodicos2.uesb.br/index.php/praxis/article/view/4375> Acesso em: 11 set. 2019.

FRANKIV, Marianna Angonese; DOMINGUES, Soraya Corrêa. Desinteresse e Proposições para Escola Atual: Contribuições do Pensamento Complexo. Tempos e Espaços em Educação, São Cristóvão, Sergipe, Brasil, v. 9, n. 19, p. 113-128, mai./ago. 2016.Disponível em:https://seer.ufs.br/index.php/revtee/article/view/5600/4616> Acesso em: 09 set. 2019.

FOLLMANN, J. I. O desafio transdisciplinar: alguns apontamentos. Ciências Sociais Unisinos. Porto Alegre, v. 41, n. 1, p. 53-57, Jan/Abr. 2005.

GODOY, A. S. A pesquisa qualitativa e sua utilização em administração de empresas.

Revista de Administração de Empresas. São Paulo, v. 35, n. 4, p.65-71, Jul./Ago. 1995.

GIL, A. C. Como elaborar projetos de pesquisa. 4. ed. São Paulo: Atlas, 2002.

MARTINS, M.; LECHUGO, C. P.; GOERGEN, P. Transdisciplinaridade: discurso ou realidade? In: CONGRESO LATINOAMERICANO DE FILOSOFÍA DE LA EDUCACIÓN, 2., 2013, Montevideo. Anais... Montevideo: Universidad de la República, 2013, p. 36-47. In: PARENTE, Nathália Prado Oliveira; NOVAIS, Jaílson Santos de. Conceitos de Interdisciplinaridade Segundo Professoras(Es) de Ciências em Santarém - Pará. Exitus, Santarém/PA, Vol. 7, N² 2, p. 217-236, Maio/Ago 2017. Disponível em: http://www.ufopa.edu.br/portaldeperiodicos/index.php/revistaexitus/article/view/308> Acesso em: 10 set. 2019

MERLEAU-PONTY, M. Phénoménologie de La perception. Paris: Gallimard, 1945.

MORIN, Edgar. Introdução ao pensamento complexo. Lisboa: Instituto Piaget, 1991. 
NICOLESCU, Basarab. O Manifesto da Transdisciplinaridade. Triom: São Paulo, 1999.

PÁDUA, E.M.M. Metodologia da pesquisa: abordagem teórico-prática. 2. ed. São Paulo: Papirus, 1997

PENA, Alexandra Coelho. Formação de Professores de Educação Infantil: Memória, Narrativa e Inteireza. Educação \& Formação, Fortaleza, v. 2, n. 4, p. 72-86, jan./abr. 2017.Disponível em: https://revistas.uece.br/index.php/redufor/article/view/124>Acesso em: 13 set. 2019.

PROGRAMA TERRITÓRIO DO BRINCAR. O Programa. Página inicial. Disponível em: $<$ https://territoriodobrincar.com.br/o-projeto/>. Acesso em 10 de jul. de 2019.

RODRIGUES, Maria Lúcia. Caminhos da Transdisciplinaridade: fugindo a injunções lineares. 2018. Disponível em:

<http://www.nemesscomplex.com.br/conteudos?id=22/caminhos_da_transdisciplinaridade__fugindo_a_injuncoes_lineares>. Acesso em: 18 jul. 2019.

SANTOS, Akiko. Didática sob a ótica do pensamento complexo. Porto Alegre: Sulina, 2004.

SANTOS, Akiko; SANTOS, Ana Cristina S; CHIQUIERI, Ana Maria C. A dialógica de Edgar Morin e o terceiro incluído de Basarab Nicolescu: uma nova maneira de olhar e interagir com o mundo. III EDIPE - Encontro Estadual de Didática e Prática de Ensino, 2009. Disponível em:

<http://www2.unucseh.ueg.br/ceped/edipe/anais/IIIedipe/pdfs/4_conferencias/conf_a_dialogi ca_de_edgar_morin.pdf >. Acesso em: 10 jul. 2019.

SILVA, Maria de Fátima Gomes. Para uma ressignificação da interdisciplinaridade na Gestão dos Currículos em Portugal e no Brasil. Lisboa: Fundação Calouste Gulbenkian Fundação para a Ciência e Tecnologia, 2009. 


\section{SOBRE AS AUTORAS:}

\section{Maria de Fátima Gomes da Silva}

Doutora em Ciências da Educação pela Universidade do Porto; Professora Adjunta da Universidade de Pernambuco - Brasil; Docente permanente do Programa de Pós-Graduação em Educação da Universidade de Pernambuco e do Programa de Mestrado em Gestão do Desenvolvimento Local Sustentável da Faculdade de Ciências da Administração e Direito FCAP-UPE. Líder do Grupo de Pesquisas Interdisciplinares em Formação de Professores, Política e Gestão Educacional e do Grupo de Pesquisas: O lugar da interdisciplinaridade no discurso de Paulo Freire. E-mail: fatimamaria18@gmail.com

(iD http://orcid.org/0000-0002-7801-2939

\section{Iolanda Mendonça de Santana}

Mestra em Educação pela Universidade de Pernambuco - UPE; Professora da Educação Básica da Rede Municipal de Ensino de Macaparana-PE. Pesquisadora do Grupo de Pesquisas Interdisciplinares em Formação de Professores, Política e Gestão Educacional UPE, Campus Mata Norte E-mail: iolanda.ms@ hotmail.com

(iD http://orcid.org/0000-0001-6493-4441

\section{Carla Fernanda Silva do Prado}

Graduanda em Pedagogia na Universidade de Pernambuco, Campus Mata Norte; Bolsista de Iniciação Científica pelo CNPq. Pesquisadora do Grupo de Pesquisas Interdisciplinares em Formação de Professores, Política e Gestão Educacional UPE, Campus Mata Norte. E-mail: carlafeeprado@outlook.com

\section{http://orcid.org/0000-0001-6170-3808}

